\title{
Epistemic Authority: Preemption or Proper Basing?
}

\author{
Katherine Dormandy ${ }^{1}$
}

Received: 29 July 2015/ Accepted: 26 May 2017/Published online: 19 July 2017

(C) The Author(s) 2017. This article is an open access publication

\begin{abstract}
Sometimes it is epistemically beneficial to form a belief on authority. When you do, what happens to other reasons you have for that belief? Linda Zagzebski's total-preemption view says that these reasons are "preempted": you still have them, but you do not use them to support your belief. I argue that this situation is problematic, because having reasons for a belief while not using them forfeits you doxastic justification. I present an alternative account of belief on authority, the proper-basing view, which enables the agent to base her belief on as many reasons as she has. A salient result is that the notion of a preemptive reason, useful though it may be in accounting for acting on authority, does not have any place in an account of believing on authority or in epistemology more generally.
\end{abstract}

\section{Introduction}

You are on an Alpine hiking tour, and the botanist leading it tells you that the purple flowers in the meadow are Bavarian gentians. On her authority, you come to believe this.

Believing on another person's authority is of epistemological interest because, under certain conditions, it has the potential to put you in a better epistemic position than you were before. This can happen when that person has many more reasons pertaining to the issue than you do and is much more skilled at evaluating them, ${ }^{1}$ and when you have no inside information that she lacks (e.g. you have not

\footnotetext{
${ }^{1}$ She is what Joyce (2007) calls a "database expert" as well as what he calls an "analyst expert", page 192; for a similar distinction see Elga (2007), page 2.
}

Katherine Dormandy

katherine.dormandy@uibk.ac.at

1 Institute for Christian Philosophy, University of Innsbruck, Karl-Rahner Platz 1,

6020 Innsbruck, Austria 
spraypainted the flowers purple behind the botanist's back; cf. Elga 2007, 3). In such cases she is in a good position-very likely a better one than you-to form a true belief in the domain. Let's call a person with these sorts of reasons and this ability to evaluate them, in circumstances where you lack inside information, an epistemic authority for you.

A normative account of belief on authority will show how the agent believing on authority can secure certain epistemic goods as a result. This is the aim of Linda Zagzebski's account. Zagzebski argues that the fact that an authority holds a belief, which we may call an authoritative reason, often gives a person a good reason to hold it himself. What distinguishes Zagzebski's view is its claim about how the authoritative reason should interact epistemically and psychologically with any other reasons which the agent may have for or against that belief. Zagzebski's view, which I'll call the totalpreemption view (for reasons to be seen momentarily), says (Zagzebski 2012, 107):

Preemption: The fact that an authority believes that $p$ is a reason for me to believe that $p$ which replaces my other reasons relevant to $p$ and is not simply added to them.

On Zagzebski's view, preemptive belief that $p$ entails that the authoritative reason becomes the only reason which the agent uses to support his belief that $p$. A natural way to understand this claim is in terms of epistemic basing. ${ }^{2}$ Understood this way, Preemption entails that the agent who believes that $p$ on authority bases this belief on the authoritative reason and no other (hence "total preemption"). Thus if the agent happens to have a reason of his own to hold the same belief as the authority, that reason goes epistemically and psychologically unutilized.

I argue that this is an epistemically sub-ideal situation to be in, for an important epistemic good hinges on the reasons you base your belief on. This good is doxastic justification, and it correlates with two important forms of truth-conduciveness. If you have several reasons for a belief but only base that belief on one of them, then you will often have a lesser degree of doxastic justification than if you base your belief on your other reasons too.

This is the position of someone who believes preemptively on authority while having reasons of his own which support the authority's belief: the total-preemption view prohibits him from including them in his epistemic basis. Because of this, he knocks against an upper limit on the doxastic justification he can enjoy. Or so I argue.

Why preempt then? Zagzebski argues that the total-preemption view is the best way to promote one central epistemic good: true belief. But I will argue that she is mistaken: believing on the basis of an authoritative reason plus any other reasons one may have can, when done in accord with the account I'll recommend, be every bit as truth-conducive as total-preempting and in some ways even more so.

Section 2 presents the total-preemption view in greater detail. Section 3 argues that this view forfeits doxastic justification, and Sect. 4 presents my positive account of belief on authority, the proper-basing view. Section 5 addresses objections, and Sect. 6 concludes.

\footnotetext{
2 This reading is also adopted by Anderson (2014) and Jäger (2015), and is accepted by Zagzebski herself Zagzebski (2016).
} 


\section{A Closer Look at Preemption}

Preemption says that an agent takes another person's belief that $p$ on authority just in case (i) he forms the belief that $p$ or continues to hold it if he already has formed it, and (ii) he does so on the sole basis of the authoritative reason, so that reason "replaces" his other reasons "and is not simply added to them" (Zagzebski 2012, $107),{ }^{3}$ regardless of whether his other reasons speak for or against $p$ : "I am believing on authority only if I take the authority's belief or testimony that $p$ as replacing my other reasons for and against p" (Zagzebski 2016, 1, italics added).

To say that a reason speaks for or against a belief is to posit a relation of evidential support between the reason and the belief. To say that a person holds a belief for a reason is to posit a psychological relation between the belief and the reason: the agent bases the belief on the reason. An agent can hold a belief and have a reason for it, ${ }^{4}$ yet not base the belief on the reason. This is what Zagzebski's conception of preempting involves. Once the agent discovers that the authority believes that $p$ (a reason I'll henceforth call $a$ ), he forms the belief that $p$ if he hasn't already, and he bases it on $a$ alone: any other reasons he has either for or against $p$ become psychologically inert. They are no longer part of his basis for his belief that $p$.

We may thus express the total-preemption view more specifically as follows:

Total Preemption: Believing that $p$ on authority amounts to basing this belief on the authoritative reason (i.e., on $a$ ), where no other reason either for or against $p$ appears in the agent's epistemic basis.

To see what Total Preemption amounts to, consider three scenarios. The first is what I'll call a no-reason scenario. Suppose that, before realizing that you-an authority for me-believe that $p$, I have no reasons either for or against $p$. On discovering your belief I acquire $a$ and form the belief that $p$. Here, Total Preemption applies trivially, since I have no other reasons which $a$ can preempt.

Next consider what I'll call a contra-reason scenario. Before acquiring $a$, I have a reason $q$ which speaks for $\neg p$, so I believe that $\neg p$ on the basis of $q$. Then I acquire $a$. Total Preemption says that I must cease to believe that $\neg p$, and form the belief that $p$ on the basis of $a$. As for $q$, assuming that it continues to speak for $\neg p$ even in the light of $a$, it clearly can't be a reason for my new belief that $p$; Total Preemption says that it is rendered psychologically inert by $a$, at least as far as the question whether $p$ is concerned. ${ }^{5}$ So far so good.

The third type of case, which I'll call a pro-reason scenario, is where the problem for Total Preemption arises (cf. Jäger 2015). Here, before acquiring $a$, I

\footnotetext{
3 The total-preemption view differs from salient accounts of epistemic deference like those of Elga (2007) and Joyce (2007), which claim only (i).

4 Zagzebski does not tell us what having a reason amounts to. A common way to understand this, and the one I'll assume, is that an agent takes the reason to be true. If the reason is experiential, what she takes to be true is a propositional articulation of it.

5 As long as $q$ itself is not undermined by $a$ or $p$, then I am still free to use it as a basis for other beliefs that are compatible with them.
} 
start off with a reason $r$ which I recognize to support $p$. Consider the following two sub-cases:

Initially Defeated Pro-Reason: As well as starting off with reason $r$ for $p$, I start off with reason $q$ for $\neg p$. $q$ defeats $r$, so I believe that $\neg p$. While in this state I receive $a$. This new reason defeats $q$, so I come to believe that $p$. One might think that now $r$ can be set free to join $a$ in my basis for $p$. But the total-preemption view forbids this. The authoritative reason $a$ supplants not just conflicting reasons like $q$, but also concurring reasons like $r$.

This result is odd. Connecting reasons one has with beliefs that they support is traditionally regarded as an important form of epistemic housekeeping. Yet Total Preemption denies my belief the support of a perfectly good reason, $r$.

Consider the second sub-case:

Undefeated Pro-Reason: I start off with $r$, a good reason for $p$ which I recognize as such, and since I have no reasons that defeat it, I believe that $p$. When I acquire $a$, however, Total Preemption says that I must cease believing that $p$ on the basis of $r$ and-while still having $r$ and recognizing that it supports $p$-I must believe that $p$ on the basis of $a$ alone.

This result is odder still. Adding reasons to our epistemic basis is traditionally regarded as a step forward. Yet the total-preemption view recommends moving in the opposite direction: it recommends unhinging a belief from a good reason you already based it on. It is hard to see how, even when you gain a still better reason, this unhinging move is anything other than an epistemic regression. ${ }^{6}$

Zagzebski claims to model Total Preemption on Joseph Raz's account of the way in which a legal authority issues preemptive reasons for action (Raz 1988). Yet Raz's notion of a preemptive reason for action works differently from Zagzebski's notion of a preemptive reason for belief. Most saliently, Raz holds that an authority's command only preempts reasons which the agent may have against performing the commanded action-not reasons he may have for performing it. For Raz, a preemptive reason is a decisive reason against acting on contra-reasons. Raz motivates this notion of preempting by saying that preemptive reasons for action

do not, of course, exclude relying on reasons for behaving in the same way as the [authoritative] directive requires. Think about it: authority improves our conformity with reason by overriding what we would do without it, when doing so would not conform with reason. So, assuming that it is entirely successful in its task, it need not and does not stop us from following the reasons on the winning side of an argument....Hence the pre-emption excludes only reasons that conflict with the authority's directive.

\footnotetext{
6 The psychological possibility of total-preempting is questioned by Jäger (2015), Anderson (2014) and Dougherty (2014).

7 Raz (2009), 145; cf. Raz (1977), 221-223.
} 
Raz even thinks that it can be better to perform the commanded action for reasons of one's own. He points out that a legal authority's prohibition of killing suffices for not killing, but that it is surely better to refrain from killing also (or indeed only) because killing is wrong (ibid., 146).

I agree with Raz that authoritative commands do not preempt reasons for acting as commanded. I'll argue that, similarly, authoritative reasons for belief do not preempt pro-reasons for believing. Just as moral goods can be gained by acting on one's own reasons as well as the authority's command, epistemic goods can be gained by believing on one's own reasons as well as the authoritative one. In particular, I'll argue that preempting in pro-reason cases sets an upper limit on the degree of doxastic justification that agents can obtain. Here is a summary of my argument, where $a$ (to recall) is the fact that the authority believes that $p$ :

\section{Argument from Doxastic Justification}

1. The total-preemption view construes belief on authority as belief on the basis of $a$ alone, rather than on the basis of $a$ and other good reasons too. (Statement of the total-preemption view)

2. Belief on the basis of $a$ plus other good reasons can often secure a greater degree of doxastic justification than belief on the basis of $a$ alone can. (The Doxastic-Justification Claim)

3. Therefore, the total-preemption view often cannot secure as great a degree of doxastic justification as believing on the basis of $a$ plus one's other reasons. (from 1, 2)

The Argument from Doxastic Justification focuses on pro-reason situations. It does not generalize to no-reason or contra-reason situations. That Total Preemption is problematic in many pro-reason cases is enough to cast serious doubt on itespecially when there is a better account available. One might think that Razian preemption (i.e., preempting only contra-reasons) would work better, but I argue that this notion of preemption, appropriate though it may be for an account of acting on authority, is not suited to epistemology. My account, the proper-basing view (Sect. 4), is completely non-preemptive.

Section 3 defends premise 2, the Doxastic-Justification Claim.

\section{Doxastic Justification}

A belief is doxastically justified to the extent that it is epistemically supported by the reasons on which the agent bases it. Doxastic justification may be contrasted with propositional justification, which a belief enjoys to the extent that the agent simply has reasons supporting it even if he does not base the belief on them. An agent who preempts pro-reasons continues to enjoy whatever propositional justification those pro-reasons yield, even if (as I'll argue) he forfeits doxastic justification. So it is natural to wonder what difference basing - and thus doxastic justification-makes over and above propositional justification. At the end of this section I'll be in a position to answer this question. 
Doxastic justification admits of degree. A person who bases his belief on sufficient supporting reasons has thereby reached a certain threshold of doxastic justification, but he can often increase his doxastic justification by adding more reasons. I claim that, at least in many cases, an agent who bases his belief that $p$ on $a$ as well as on his own pro-reason $r$ has greater doxastic justification than an agent who bases his belief on $a$ alone. The reason is this:

The Epistemic-Support Claim: In many cases, the two reasons $a, r$ offer better epistemic support to $p$ than the single reason $a$ does on its own.

The total-preemptionist will deny the Epistemic-Support Claim. She might argue, for example, that once the agent has acquired $a, r$ is no longer epistemically relevant-thinking that it is amounts to double-counting $r$. For if $r$ is a good reason for $p$, then it is already likely to feature in the authority's own epistemic basis. Keren (2007) argues that "just to add [the authority's] judgment to those reasons which are accessible to me would amount to double-counting of those reasons that are accessible to both of us" (374). ${ }^{8}$ If the double-counting objection is correct, then the Epistemic-Support Claim is false and Premise 2 undermined.

I'll offer two arguments for the Epistemic-Support Claim, each of which focuses on a different variable that determines epistemic support: the confirmation of a belief by a reason, and the weight of a body of reasons. We'll see for each variable why the double-counting objection is mistaken.

\subsection{Confirmation}

A reason confirms a belief to the extent that the belief is more probable given that reason than without it. Why should we care about confirmation? Because the more strongly your belief is confirmed, the higher the confidence with which you are epistemically entitled to hold it. You can be surer in the inferences you draw from your belief and in the actions you perform in the light of it.

Confirmation and confidence can come apart: you can hold your belief more or less confidently than the confirming strength of your reasons warrants. When you are more confident than your reasons warrant, then you have jumped to conclusions and your belief lacks sufficient doxastic justification. When you are less confident than your reasons warrant, then you forfeit the full doxastic justification you are entitled to. In both types of case, something has gone amiss with your epistemicbasing relation.

This section argues that many cases of total preemption fall under the second category: $a$ with $r$ warrants greater confidence in $p$ than $a$ without $r$ does. So when you have $r$ but preempt it, your basing behavior does not reflect the full force of your reasons and you forfeit doxastic justification-you wind up less confident than

\footnotetext{
8 This objection might seem to derive from Razian considerations, for Raz (1977) argues that a preemptive reason for acting "merely relays the force of the reasons for" performing the action (221). But any similarity to Raz withers on closer inspection. Raz does not take it to follow that the agent's own reason is therefore redundant. On the contrary, we saw in the no-killing example in Sect. 2 (cf. Raz 2009, 146) that he thinks that the non-authoritative reason can add value to the action.
} 
you are entitled to be. To show this, I will argue that, in certain sorts of pro-reason case, the following claim is true:

Greater-Conf: $p$ receives greater confirmation when $r$ and $a$ obtain together than when $a$ obtains without $r$.

Greater-Conf does not apply all the time. ${ }^{9}$ It is restricted to what I'll call informedamateur cases: cases in which the agent has done some independent research into the domain and so knows a little bit about it, but is by no means an expert; and the domain is not totally unfathomable for non-experts. I take it that there are enough informed-amateur cases out there to make serious trouble for Total Preemption.

I'll begin with some stipulations about $r$ and $a$. First, they are logically consistent. Second, they are logically independent: sometimes authorities hold beliefs even when other reasons fail to obtain, and sometimes reasons obtain even when no authorities hold the beliefs that those reasons support. Third, neither $r$ nor $a$ lowers the probability of the other. Indeed, they will typically raise each others' probability: the fact that an authority believes that $p$ raises the probability that other good reasons for $p$ obtain, and the fact that a good reason for $p$ obtains makes it more likely that an authority believes that $p$.

Let's look more closely at the alternative evidential scenarios that my argument will compare:

$e_{1}$ The agent has $a$ and no other reason relevant to whether $p$.

$e_{2}$ The agent has $a$ as well as $r$.

That is, in $e_{1}$ the agent does not know whether any reasons other than $a$ obtain, and in $e_{2}$ he knows that $r$ obtains as well as $a$. These scenarios are logically incompatible.

Greater-Conf, the claim that I'll argue for, says that $e_{2}$ confirms $p$ more than $e_{1}$ does; that is, $p$ 's probability given $e_{2}$ (in informed-amateur cases) is higher than its probability given $e_{1}$. We may express Greater-Conf formally:

$$
\text { Greater-Conf }_{\text {formal }}: \operatorname{Pr}\left(p \mid e_{2}\right)>\operatorname{Pr}\left(p \mid e_{1}\right)
$$

I'll begin my argument for Greater-Conf $f_{\text {formal }}$ by restating it in an equivalent form that is more tractable for present purposes. Bayes's Theorem ${ }^{10}$ gives us the definition of conditional probability (at least when the denominator is defined), letting us express Greater-Conf formal $_{\text {like this: }}$

$$
\text { Greater-Conf }_{\text {Bayes }}: \frac{\operatorname{Pr}\left(e_{2} \mid p\right) \operatorname{Pr}(p)}{\operatorname{Pr}\left(e_{2}\right)}>\frac{\operatorname{Pr}\left(e_{1} \mid p\right) \operatorname{Pr}(p)}{\operatorname{Pr}\left(e_{1}\right)}
$$

\footnotetext{
${ }^{9}$ For example, it does not apply when $r$ 's status as a reason for the agent depends causally on $a$ 's status as a reason. Here, because the agent learned $r$ from the authority, $a$ screens $p$ off from $r$; i.e., $\operatorname{Pr}(p \mid a)=\operatorname{Pr}(p \mid a \wedge r)$.

${ }^{10}$ Bayes's Theorem: $\operatorname{Pr}(H \mid E)=\frac{\operatorname{Pr}(E \mid H) \operatorname{Pr}(H)}{\operatorname{Pr}(E)}$.
} 
In the numerator of each fraction, $\operatorname{Pr}(p)$ can be eliminated; this gives us, for each evidential scenario, what is sometimes called the "Bayesian Multiplier": ${ }^{11}$

$$
\text { Greater-Conf }_{\text {multiplier }}: \frac{\operatorname{Pr}\left(e_{2} \mid p\right)}{\operatorname{Pr}\left(e_{2}\right)}>\frac{\operatorname{Pr}\left(e_{1} \mid p\right)}{\operatorname{Pr}\left(e_{1}\right)}
$$

Greater-Conf multiplier $_{\text {is logically equivalent to Greater-Conf }}$ formal . What Greater-

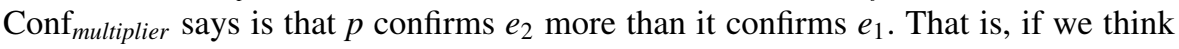
about how much the truth of $p$ boosts the probability that our agent has $a$ and $r$, as opposed to how much the truth of $p$ boosts the probability that he has $a$ and no other reason, it will become apparent that $p$ has a greater impact on the probability of the former scenario, $e_{2}$.

To see why, consider how $p$ 's truth affects the probability of $e_{1}$, that an informed amateur believes that $p$ solely on the basis of an epistemic authority. I take it that $p$ 's truth does confirm this scenario. For if $p$ is true, then we would expect authorities about the domain to believe it, and we would expect informed amateurs to consult them and thus to believe that $p$ on their authority. But $p$ 's truth gives more confirmation to a scenario in which the informed-amateur agent has an independent reason beyond $a$-that is, to $e_{2}$. Why? First, because $p$ is true-so we should expect the state of affairs that it denotes to leave traces of itself in other places than just the minds of epistemic authorities. After all, they have to base their belief in $p$ on something. Second, informed amateurs have done some research and so can be expected to turn up reasons that they can understand, as long as the domain is not unfathomable to non-experts. Third, in informed-amateur situations the domain is not unfathomable to non-experts. $p$ confirms $e_{2}$, then, more than it confirms $e_{1}-$ Greater-Conf multiplier $_{\text {is true. }}$

Because Greater-Conf multiplier $_{\text {is equivalent to Greater-Conf }}$ formal, the latter is true as well. I conclude that, in informed-amateur cases, $\operatorname{Pr}\left(p \mid e_{2}\right)>\operatorname{Pr}\left(p \mid e_{1}\right)$. Having a fairly good reason $r$ and an authoritative reason $a$ confirms $p$ more than having just $a$.

This means that, in informed-amateur cases, an agent with $r$ and $a$ is entitled to believe that $p$ with greater confidence than he would be if he only had $a$. Yet the total-preemption view forfeits him that higher degree of confidence, saying that he must instead believe that $p$ with the lower degree of confidence commensurate with his having $a$ and no additional reasons. An agent who engages in this sort of epistemic-basing behavior loses out on doxastic justification. My argument affords the following answer to the double-counting objection: if $r$ were really doublecounted, then it would not be possible for it to add to $a$ 's confirmation of $p$.

\subsection{Weight}

My second argument for the Epistemic-Support Claim pertains to another variable that determines epistemic support: the weight of a body of reasons. I argue that an epistemic basis containing $a$ and $r$ often weighs more heavily with respect to $p$ than

11 See e.g. Strevens (2012), 30. 
one with just $a$ does. What does this mean and why should it matter? As Joyce (2005) puts it, the weight of a body of reasons "is a matter of the gross amount of relevant data available. It is reflected in the concentration and stability of probabilities in the face of changing information" (154). A weightier body of reasons provides you with a "more settled picture of the situation" (161). Hence the weightier the reasons on which you base a belief, the more stable that belief will tend to be in the face of changing information.

For example, imagine that you are conducting a random telephone interview across the UK about people's views on the Brexit referendum. In one scenario your team has interviewed 100 people. 50 plan to vote "remain", 40 "leave", and 10 are undecided. You set your probability for "remain" at 50\%. In the second scenario your (larger) team has interviewed 100,000 people. 50,000 plan to vote "remain", 40,000 "leave", and 10,000 are undecided. Here too you set your probability for "remain" at $50 \%$. Even though your probability is the same in both cases, in the second case it is more stable. Interviewing ten more people, all of whom plan to vote "leave", will completely upend your credence in the first scenario but will hardly dent it in the second. ${ }^{12}$

An epistemic basis containing $a$ as well as $r$ often has greater weight with respect to $p$ than one containing just $a$. This is because $r$ is a different piece of information than $a$ : it says something about whether $p$ independently of the authority's expert status. ${ }^{13}$ To see this, suppose that your total epistemic basis consists in $a$ and $r$. If you subsequently discover that $r$ is false, you can often keep believing that $p$ on the basis of $a$ alone (for surely the authority has other reasons). Similarly, if you discover that $a$ is false (say, the so-called authority turns out to have plagiarized her credentials), then you can often keep believing that $p$ on the basis of $r$ alone.

The double-counting objector may concede that $a$ and $r$ weigh more than $a$ alone when you don't know whether $r$ was one of the authority's own reasons, but deny that it holds when you know that it was. In the latter case, she will say, $r$ is not additional information to $a$, but is instead included in $a$ itself. But the objector is mistaken. Even if you know that $r$ is among the authority's reasons, it is still an independent piece of information for you. We can see this by noting that, if the authority is debunked, $r$ does not thereby turn out false, unless additional details are added to the case which link $a$ with $r$. Nor, without additional details, will $r$ thereby turn out not to support $p$ after all. Discovering that your botanist is a fraud does not undermine the independent reading that you did before the hiking tour. Hence even when you know that the authority bases her belief that $p$ on $r, a$ together with $r$ often has greater weight vis-à-vis $p$ than $a$ does by itself.

The total-preemptionist might object that, even if this is true, there are no adverse consequences to preempting $r$ with $a$. If the authority is debunked, you can simply reinstate $r$ and continue believing that $p$ uninterrupted. But this is a seriously subideal fix. First, there is no guaranteeing that you could easily re-instate $r$-in your

\footnotetext{
12 Of course, weightier reasons make your belief more sluggish to confirm, but this just reflects the goodness of already having weighty reasons.

${ }^{13} r$ and $a$ themselves are not probabilistically independent (i.e., from the agent's point of view the probability of one affects the probability of the other), but this does not change the fact that one could prove false without vitiating the other's support for $p$.
} 
zealous and exclusive reliance on the authority, you might have forgotten $r$. Second, even if you do re-instate $r$, nothing changes the fact that, as long as $a$ was your only reason, your belief relied on a bogus reason. Total Preemption takes a great risk in obligating agents who believe on authority to put all of their epistemic eggs in one basket when others are available. If this risk secured anything of value in return, it might be worth it. But as things stand there seems little reason to exclude $r$ from your epistemic basis for $p$, and much reason to include it.

In conclusion, the Epistemic-Support Claim is true, and twice over. In pro-reason situations the total-preemption view often forfeits the agent two important aspects of doxastic justification: confirmation and weight.

We are now in a position to say why doxastic justification is epistemically better than mere propositional justification. Basing your belief in accord with the confirming strength of your reasons amounts to having the full degree of confidence that those reasons entitle you to, and basing it in accord with the weight of your reasons confers a stronger psychological staying power on your beliefs. If you are merely propositionally justified but leave some reasons out of your epistemic basis, you forfeit some of that entitled confidence and some of that psychological durability. Moreover, reasons tend to point toward the truth. So to the extent that your basing behavior matches the strength and weight of your reasons, your doxastic state will tend to correlate better with reality. Forfeiting doxastic justification, even if you maintain propositional justification, is a big sacrifice.

\subsection{Objection: Proportional Truth-Conduciveness}

Even if Zagzebski accepts the Epistemic-Support Claim, she might argue that forfeiting doxastic justification is a bullet we must bite in order to preserve another important epistemic good. Doing anything other than total-preempting, she says, "will worsen my track record in getting the truth" (Zagzebski 2012), 114.

What does she mean by this? She cannot mean that total-preempting secures higher probabilities in truths or improves the diachronic stability of a true belief. We just saw that, in these respects, not preempting can be more truth-conducive than preempting. What Zagzebski has in mind is this: she thinks that, out of a range of (hypothetical) cases in which an agent discovers what an authority believes, totalpreempting produces a higher proportion of true beliefs than basing his belief on his other reasons too. Let's call this third form of truth-conduciveness proportional truth-conduciveness.

Why does Zagzebski think that total-preempting is more proportional-truthconducive than not preempting? Because she has a particular way of not preempting in mind: the agent "treats an authority's belief as evidence of the truth of the belief that ought to be added to [his] other evidence, ...perhaps weighing the authority's belief more heavily than [his] other reasons" (Zagzebski 2012, page 114). In other words, the agent evaluates his total pro- and contra-reasons such that $a$ is just one among the former, and bases his final belief on whichever subset of these reasons has greater force, where there is a live chance that it might be the contra-reasons.

Let's call this form of non-preemption the aggregate-basing view, and spell it out like this: 
Aggregate-Basing: Believing that $p$ on authority amounts to basing this belief on the authoritative reason and on any other reasons you may have, where (i) proreasons exert force for $p$ and (ii) contra-reasons exert force against $p$.

Why should Aggregate-Basing basing be less proportional-truth-conducive than Total Preemption? In undefeated pro-reason situations it will not be, since none of the agent's reasons weighs against the authority's belief to begin with. But whenever the agent starts with a contra-reason, that reason may sometimes be forceful enough that it sways him to keep his original belief rather than adopt the authority's. Yet since the authority is a more reliable gauge of the truth than he is, his overall rate of mistakes will tend to be greater than hers (114). ${ }^{14}$

This line of thought is reasonable as far as it goes. Precisely because the authority is an authority (and the agent is not), the agent has a higher probability of believing truly if he follows her; he should thus treat her beliefs as akin to a chance function. And this means letting the authoritative reason swamp any reasons he may have against her belief. If she were some lesser form of epistemic superior (such as what Elga 2007, 3, calls a "guru"), believing on her authority would not be appropriate to begin with (see Sect. 4 for more discussion). ${ }^{15}$

Thus on the face of it we have a quandary. If we choose Total Preemption, then when we have contra-reasons we'll do well on proportional truth-conduciveness, but when we have pro-reasons we'll forfeit doxastic justification and thus the other two kinds of truth-conduciveness. If we choose Aggregate-Basing, then when we have pro-reasons we'll do well on doxastic justification and the associated forms of truthconduciveness, but when we have contra-reasons we'll do poorly on proportional truth-conduciveness.

Fortunately, this quandary can be easily resolved by taking the best of both views. The result is a view that advocates preempting contra-reasons and basing one's belief on an aggregate of pro-reasons. This should look familiar: it is an epistemological analogue of Joseph Raz's account of action on authority. Recall from Sect. 2 that Raz construes a preemptive reason as a decisive reason against acting in accord with a contra-reason. Pro-reasons are not preempted. Raz states his preemption thesis for acting on authority like this: "The fact that an authority requires performance of an action is a reason for its performance which is not to be

\footnotetext{
14 Zagzebski takes this argument from Raz (1988), 68-69. But Raz does not use it to argue that authoritative reasons for acting preempt all of the agent's other reasons. Rather, his view (recall Sect. 2) is that authoritative reasons for acting preempt only contra-reasons; cf. Raz (2009), 145; Raz (1977), 222. Zagzebski thus draws a stronger conclusion from Raz's argument than Raz does himself.

15 Keren (2014) observes that it does not follow from Zagzebski's argument that adopting the authority's belief is always epistemically better for the truth-motivated agent in a contra-reason situation. Whether it is, he notes, is a function of the extent to which the agent is averse to the risk of falsehood. We may add that it is also a function of the epistemic distance between the agent and the authority. Suppose that the authority's success rate is merely $70 \%$ to the agent's $60 \%$. Although the agent's probability of scoring a true belief is higher by following the authority than by following his independent judgment, it is a mere $10 \%$ higher. This may not be enough to justify the risk-averse agent in adopting the authority's belief against his own judgment. Yet the authority's disagreement should prompt him to shy away from following his independent judgment, as well. For the risk-averse agent, suspension of belief altogether may be the epistemically best option. But the fact remains that, for anyone willing to risk belief, preempting contra-reasons is the better option.
} 
added to all other relevant reasons when assessing what to do, but should replace some of them" $\operatorname{Raz}$ (1995), 215, where he makes it clear that the "some of them" refers to contra-reasons Raz (2009), $141 .^{16}$ Here is an epistemic analogue of Raz's view:

Contra-Reason Preemption: Believing that $p$ on authority amounts to basing this belief on the authoritative reason and any other pro-reason you may have, where the authoritative reason is not to be added to all other relevant reasons when assessing what to believe, but should replace any reasons for believing that $\neg p$.

Contra-Reason Preemption optimizes proportional truth-conduciveness and doxastic justification and so is superior both to the total-preemption view and to the aggregate-basing view.

Yet it is not the account I will ultimately advocate. There is a subtle yet important theoretical worry facing it which yet a fourth view-which achieves the same result - can ameliorate. I'll introduce my proposed view, the proper-basing view, and then contrast it with Contra-Reason Preemption.

\section{The Proper-Basing View of Belief on Authority}

The proper-basing view says this:

Proper-Basing Belief on Authority: Believing that $p$ on authority amounts to basing this belief on the authoritative reason and any other reasons you may have, where (i) pro-reasons exert a force for $p$ and (ii*) contra-reasons do not exert any force against $p$.

Proper-Basing resembles Aggregate-Basing, with one exception: the proper-basing view asserts (ii*) instead of (ii). This is a marked improvement, since it is (ii), the claim that contra-reasons can exert force against $p$, which gets the aggregate-basing view into trouble with proportional truth-conduciveness. The problem there was that, in the tally of reasons concerning whether $p$, Aggregate-Basing counts contrareasons negatively. The proper-basing view says instead that contra-reasons neither add nor subtract from the tally. Their evidential force is zero.

To see why, note that the force of a reason is relative to background information. For example, against the background information that the lighting is normal, a perceptual experience of a green necktie is a forceful reason for believing that the tie is green. But against the background information that the lighting is green, this perceptual experience loses all force whatsoever. I submit that authoritative reasons have this force-depleting effect on contra-reasons. An epistemic authority is by definition as good a gauge of the truth as can usually be found. Being an authority,

\footnotetext{
${ }^{16}$ More specifically, the contra-reasons in question are those which it is the authority's responsibility to take into account; we may ignore this detail in the epistemic case, where it is the authority's responsibility to take into account as many epistemic reasons as possible pertaining to whether $p$.
} 
she not only has many more reasons than the agent, but is more skilled at evaluating them. So relative to an authoritative reason, contra-reasons exert no force against $p$ at all. If a contra-reason $q$ obtains, then the agent can safely suppose that the authority has already taken it into account and come to believe that $p$ in spite of it. The fact that $a$ obtains is powerful evidence that $q$ is either false or does not support $\neg p$ after all. ${ }^{17}$ This is the way in which the proper-basing view cashes out the claim, made in Sect. 3.3, that the authority's belief should be treated like a chance function-once you discover the physical chance of an event, your reasons for thinking that its chance is otherwise are typically undermined as reasons. ${ }^{18} \mathrm{We}$ might express this by saying that an authoritative reason is a rebutting defeater for belief that $\neg p$, since it is a reason for believing that $p$ which cancels any reasons you may have against $p$.

Proper-basing achieves the same result as contra-reason preempting (i.e., it reaps the benefits of having multiple pro-reasons in your epistemic basis, while remaining undiluted by any negative impact of having contra-reasons in that basis). But these views differ in the way that they achieve this result when dealing with contrareasons: contra-reason preempting achieves it by psychologically sidelining contrareasons, whereas proper-basing achieves it by letting the natural interplay of reasons do its epistemic work.

Why prefer Proper-Basing to Contra-Reason Preemption, if both achieve the desired result? To answer this question I'd like to highlight a feature of preemptive reasons. In the right circumstances, they can override reasons which have not lost their force. Consider for example a legal authority who issues a command that the agent recognizes does not conform to the total reasons that apply to the agent-a judge has overstepped her bounds or made an unfair ruling. In many legal structures, the agent must regard her command as preemptive nonetheless. If there is a higher authority he may appeal her decision, but unless and until a higher authority has overturned it, he is stuck abiding by it. Raz says, "Even legitimate authorities make mistakes. In such cases we should conform with the directive", (Raz 2009), 146. In this situation, the agent's contra-reasons still have force: in a tally of his total reasons for acting as the authority has commanded, they would pull against doing so. But these reasons are preempted, so their force goes uncounted in this case. Indeed, it is precisely because these reasons maintain their force that they must be preempted at all.

This feature of preemptive reasons is useful in cases of practical authority. Legal authorities are there (among other reasons) to preserve order and they do so most effectively when their commands preempt. Arbitration, for example, would never get off the ground if the parties did not bind themselves in advance to the

\footnotetext{
17 One might object that I am guilty of special pleading, claiming that an account of belief on authority should treat contra-reasons differently from pro-reasons. But this is not what I am saying; both types of reason should be treated the same. What I am saying instead is that both types of reason have their force at least partly determined by the background information.

${ }^{18}$ Raz agrees with this assessment of the force of contra-reasons in the epistemic case: "[o]nce their authority as experts is established, it follows that our non-expert evaluations of the same evidence cannot reliably challenge theirs" (Raz 2009), 156.
} 
arbitrator's decision. ${ }^{19}$ But in the case of epistemic authority, this feature of preemption is less useful. There, contra-reasons lose their force as a matter of course anyway. So agents will never be called upon to believe against the force of their contra-reasons, because, in the light of the authoritative reason, those contra-reasons will not have any force to begin with.

A fan of Contra-Reason Preemption will ask why this overriding-ability of preemptive reasons should bother us if, as I have just conceded, it will never be activated in cases of belief on authority anyway. In response, I'd like to insist on proper-basing precisely because this feature of preemption will never be activated in the epistemic case. There is no need to exclude contra-reasons from the tally of our total reasons. They can remain there because the force they contribute to the total sum will always, as long as the authority remains an authority, be zero. Preempting them is a redundant manoeuvre. It is like muzzling a toothless dog.

But there is a deeper reason for declining to conceptualize belief on authority in terms of preempting, even when it is only contra-reasons that are preempted. To see what it is, note that the function of reasons is to secure epistemic goods like truth and doxastic justification. Reasons exercise this function by having a particular force relative to an agent's background reasons. This means that it is highly questionable whether a normative epistemology should ever need to recommend preempting at all. Heeding the force of reasons is what puts us in a position to reap their benefits, so their force alone should suffice to determine what we ought epistemically to do with them. Indeed, the preemption of contra-reasons has typically kept dubious epistemic company. Think of leaps of faith that go against the balance of our reasons. ${ }^{20}$ There may sometimes be pragmatic reasons to preempt reasons to disbelieve, but it is hard to see how there could ever be epistemic ones. Preemptive reasons, though useful in the theory of rational action, have no place in the theory of rational belief.

The contra-reason preemptionist might push back by denying that contra-reasons must lose all of their force in situations of belief on authority. She may concede that they may lose it sometimes, but insist that, at other times, the authority might not have a much better success rate than you at forming true beliefs in the domain. On your reasoning, $q$ might remain a potent objection, so the only way to win proportional truth-conduciveness is to remove it from your tally.

In response, if the objector is right that $q$ does not lose all of its force relative to $a$, then $q$ should factor into your reasoning about whether $p$ ! To see this, let's ask under what circumstances $q$ would maintain any force relative to $a$. The answer is that they are circumstances in which your interlocutor is not an authority after all, but some lesser form of epistemic superior, such as what Elga (2007) calls a "guru" as opposed to a full-fledged "expert" (3). In such cases, belief on authority is too

\footnotetext{
${ }^{19}$ Raz says that, in agreeing in advance to obey the judge's decision, "the disputants agreed to follow his judgment of the balance of reasons rather than their own. Henceforth his decision will settle for them what to do" (Raz 1995), 213-214.

20 A leap of faith which goes against the balance of one's reasons is to be distinguished from one which goes "beyond" the balance of one's reasons; the former occurs when reasons come down decisively against belief, and is uncontroversially epistemically irrational; the latter occurs when reasons are indecisive and is sometimes argued to be rational (James 1921).
} 
strong a form of deference to be appropriate; a lesser form is called for, such as what Joyce (2007) calls "strong deference" (as opposed to "complete deference") (190). This involves bringing your degree of belief closer to your interlocutor's, but not adopting it completely. ${ }^{21}$ The relationship of a $\mathrm{PhD}$ student and a supervisor might be like this: the student has achieved enough autonomy in the field that his opinions cannot simply be nullified by his supervisor's, but not so much autonomy that they count as equal to hers. Hence if contra-reason preemptionists still insist that $q$ maintains its force in the light of $a$, they must explain how $q$ 's keeping its force is compatible with regarding your interlocutor as an epistemic authority.

In summary, if the case is really a case of belief on authority rather than of some lesser form of epistemic deference, $q$ loses its force relative to $a$. When we let reasons do their allotted work, preempting is redundant. And preempting belongs more generally to the realm of action, not of belief.

\section{Objections}

\subsection{Our Evaluative Behavior}

One might object to Proper-Basing Authority because one thinks that we simply do not construe authoritative reasons in the way that it prescribes. Keren (2014) for instance argues that some of our epistemic evaluations are premised upon the goodness of preempting over and above employing all of our reasons. He claims that we think it appropriate to criticize novices who, when faced with an expert's opinion, do not preempt; for example, we criticize "laypersons [who] should defer to the authority of scientists but...refuse to do so, or children [who] refuse to defer to the epistemic authority of their parents" (64). He also claims that we consider it inappropriate, when someone has preempted given expert opinion, to criticize her for not "weigh[ing] all the relevant evidence available" (ibid.).

In response, such behavior does prompt certain epistemic evaluations, but I don't think Keren has succeeded in isolating them. Consider the stubborn layperson. We do criticize such people-but not for failing to preempt. Rather, we criticize them for continuing to hold their beliefs even after discovering that an authority (whom they recognize as such) believes the opposite. We do this regardless of the constellation of this person's epistemic basis. What about the person who preempts pro-reasons instead of counting them in the tally of epistemic support for his belief $?^{22}$ If criticism is inappropriate here, it is not because this person preempted his pro-reasons. It is because, in believing on authority, he has formed what is likely a true belief and has secured a good amount of doxastic justification. But nonetheless, I have argued that, if this person has reasons of his own which he omits from his epistemic basis, he winds up in an epistemically sub-ideal situation: he

\footnotetext{
21 Dougherty (2014)'s terminology differs from mine: he calls lesser forms of deference "belief on authority" too.

22 Note that he will have weighed his evidence for ascribing authority to begin with.
} 
could easily have more doxastic justification than he does. Our evaluative behavior does not support preempting.

\subsection{Deliberative versus Theoretical Reasons}

One might think that Epistemic Authority contains the resources to resist my argument. Zagzebski distinguishes two types of reason which, she claims, "do not aggregate"; this means that "there is no system of adding together both kinds of reason for believing $p$ to give a summary verdict on the reasonableness of believing $p$ " (66). Theoretical reasons are "facts (or true propositions)" which are "logically or probabilistically connected to the truth of p" (64). They are mind-independent, so that the "connections between theoretical reasons and what they are reasons for are among the facts of the universe" (ibid.). Deliberative reasons, by contrast, are psychological states, including experiences, emotions, and intuitions. Deliberative reasons "have an essential connection to me and only to me in my deliberations about whether $p$ " (ibid.).

How might this distinction help her resist my argument? Zagzebski says at one point that the authoritative reason "is a deliberative...reason like trust in the self or trust in others" (114). If $a$ is deliberative and a given $r$ theoretical, then, given their incommensurability, it would be incoherent to suggest that they could be combined as a basis for $p$.

Before responding we must note that it is unclear how the claim that $a$ is deliberative is compatible with the preemption view itself. For the latter says that "[t]he fact that the authority has a belief $p$ is a reason for me to believe $p$ that replaces my other reasons relevant to believing $p$ " (107, italics added); yet facts are theoretical, not deliberative. One might think that Zagzebski is claiming that the agent's trust in the authority (which is a deliberative reason) offers necessary epistemic support for the belief that she is an authority (call it $a^{*}$ ), relative to which $a$ supports $p$. But this cannot be the right reading. For if $a^{*}$ is deliberative, then it cannot aggregate with (the theoretical) $a$. And if $a^{*}$ is theoretical, then it cannot aggregate with the (deliberative) trust on which it must be based.

But even supposing that there is a plausible reading of Zagzebski's distinction between deliberative and theoretical reasons, there are further problems with it. First, it is implausible that deliberative and theoretical reasons are incommensurable at all. It seems a regular feature of belief formation that experience-like reasons combine with fact-like reasons. Consider: I feel trust in you (a deliberative reason) and then learn that you took good care of my neighbor's plants while she was away (a theoretical reason). I might believe on the basis of either reason that you'll reliably feed my cat next week, but on the basis of both I believe this more firmly yet. $^{23}$ Moreover, the incommensurability claim has odd epistemic consequences. Consider: I feel trusting of you (a deliberative reason), which we'll suppose suffices for believing that you'll take good care of my cat. But I then learn that you often forgot to lock my neighbor's door after watering her plants (a theoretical reason). If these reasons are incommensurable, then I cannot combine them to form a nuanced

${ }^{23}$ cf. Dougherty (2014), 52. 
view of your trustworthiness - say, that you are basically trustworthy but sometimes absent-minded. I can only believe on the basis of one or the other, either that you are hopelessly untrustworthy or a fortress of reliability. Yet neither verdict, given both reasons, is accurate. The incommensurability claim has little to recommend it.

But second, even if deliberative and theoretical reasons are incommensurable, this does not entail that $a$ and $r$ cannot both feature in an epistemic basis for $p$. For regardless of whether $a$ is deliberative or theoretical, it will still be able to combine with any other reason $r$ of the same type. Hence it is perfectly coherent to say that $a$ and $r$ together support $p$.

\subsection{The Metaphysics of Basing}

A final objection questions not the coherence but the metaphysical possibility of basing a belief that $p$ on two reasons. As yet I have steered clear of the discussion of epistemic basing, but a widespread account of it might be thought to spell trouble for the proper-basing view: the causal account. This account of basing says that a belief that $H$ is based on a reason $E$ just in case the latter causally sustains the former (in a non-deviant way). ${ }^{24}$ That is, $E$ causally contributes to the agent's continuing to believe that $H$, in a way which is nontrivial yet which excludes all of the ways in which a reason might sustain a belief yet intuitively not count as its basis.

One might question whether the proper-basing view of belief on authority is compatible with causal basing. To see this, note that the proper-basing view says that my belief that $p$ is epistemically overdetermined by my having reasons $r$ and $a$, since both are sufficient reasons for $p$. A causal account cashes this out as causal overdetermination — of which some (e.g. Bunzl 1979) deny the existence. ${ }^{25}$ If there is no causal overdetermination, then it might seem that causal basing is incompatible with my belief's being based on $a$ and $r$.

I have two responses. One is that, even if there were an incompatibility here, the apparent ubiquity of situations in which people base beliefs on multiple reasons would speak for the proper-basing view and against either the causal account of basing or the claim that causation cannot be overdetermined. Second, however, there in fact is no incompatibility. Even if there is no causal overdetermination, beliefs can be causal-based on more than one reason.

To see this we must be clear about the kind of causal overdetermination at issue: it is what Funkhouser (2002) calls "independent overdetermination", in which the two overdetermining causal events are logically and metaphysically independent of each other. An example is a piñata's being smashed simultaneously by two partygoers, each of whose blows would have sufficed to smash it without the other's.

If there is no independent causal overdetermination, then, as Bunzl argues (ibid.), there must be something else going on when an effect appears to be overdetermined.

\footnotetext{
${ }^{24}$ See e.g. Dretske (1999), Goldman (2001), and Swain (1981). Accounts with causal components include Audi (1986) and Korcz (2000).

25 For an argument against the existence of causal overdetermination, see Bunzl (1979). For an argument in favor, see Schaffer (2003).
} 
We might understand this in terms of what he calls "cooperative causation", in which $C_{1}$ and $C_{2}$ each make a partial contribution to bringing about $E$. The properbasing view could be cashed out in terms of this latter option. Suppose that causally sustaining my belief that $p$ requires $x$ units of neural signaling: my having reason $r$ would contribute $x-y$ units and my having reason $a$ would contribute the remaining $y$ units. Whether this suggestion is compatible with neural chemistry must of course be empirically investigated but I see no reason for doubting that-in the event that there is no causal overdetermination as such-the causal determination of a belief by two reasons can be spelled out in this way.

I conclude that, even if there is no independent causal overdetermination, a causal account of basing is compatible with the proper-basing view.

\section{Conclusion}

Zagzebski's total-preemption view of belief on authority presents an innovative normative account of an important epistemological phenomenon, aiming to spell out this phenomenon in a way that secures epistemic goods for the agent. One of its chief insights is that an authority's holding a belief often gives the agent a powerful reason to hold it himself.

Yet this view is premised upon a problematic account of which sorts of reasons are to be preempted. Not only does it mandate psychologically quarantining any reasons that speak against the authority's belief, it also mandates quarantining those which speak for that belief. This forfeits the agent doxastic justification and some important forms of truth-conduciveness. And pace Zagzebski, preempting is not the best way to gain proportional truth-conduciveness either.

One might address this problem by adopting an account which preempts contrareasons only (and thus draw closer to her original Razian inspiration). But I have argued more generally that preempting does not have a place in an account of belief on authority to begin with. The force of reasons does the epistemic work instead: because the force of contra-reasons reduces to nothing against the backdrop of an authoritative reason, they do not detract from the authority's belief at all. This is the jist of the proper-basing view of belief on authority, which accounts for the epistemic goodness of belief on authority in a simple way that reflects the epistemological purpose of reasons. Epistemology should have little need to prescribe preempting, as long as we let reasons do their work.

Fortunately, Zagzebski's larger project in Epistemic Authority does not preclude her adopting a proper-basing account of belief on authority. It would take another paper to show how, but I believe that such an account would mesh better with the rest of her project than the total-preemption or even the contra-preemption view. Zagzebski's larger aim is to argue that belief on authority is compatible with a robust form of epistemic autonomy (chapter 11). Basing your belief on your own reasons as well as an authoritative reason, I suggest, allows for an important form of epistemic autonomy which (as far as I can tell) does not contradict other aspects of Zagzebski's project. So this paper may be regarded as a friendly suggestion for serving Zagzebski's own aims even more effectively. 
Acknowledgments Thanks to the Austrian Science Fund (FWF) for open access funding and for funding to write this paper. For helpful comments and discussion I am grateful to Christoph Jäger, Lukas Kraus, Winfried Löffler, Christian Tapp, and two anonymous referees for Erkenntnis.

Open Access This article is distributed under the terms of the Creative Commons Attribution 4.0 International License (http://creativecommons.org/licenses/by/4.0/), which permits unrestricted use, distribution, and reproduction in any medium, provided you give appropriate credit to the original author(s) and the source, provide a link to the Creative Commons license, and indicate if changes were made.

\section{References}

Anderson, C. (2014). Epistemic authority and conscientious belief. European Journal for Philosophy of Religion, 6(4), 91-99.

Audi, R. (1986). Belief, reason and inference. Philosophical Topics, 14(1), 27-65.

Bunzl, M. (1979). Causal overdetermination. The Journal of Philosophy, 76(3), 134-150.

Dougherty, T. (2014). Zagzebski, authority, and faith. European Journal for Philosophy of Religion, 6(4), 47-59.

Dretske, F. (1999). Knowledge and the flow of information. Stanford, CA: CSLI Publications.

Elga, A. (2007). Reflection and disagreement. Noûs, 41(3), 478-502.

Funkhouser, E. (2002). Three varieties of causal overdetermination. Pacific Philosophical Quarterly, 83(4), 335-351.

Goldman, A. (2001). Internalism exposed. In H. Kornblith (Ed.), Epistemology: Internalism and externalism (pp. 207-230). Malden, MA: Blackwell.

Jäger, C. (2015). Epistemic authority, preemptive reasons, and understanding. Episteme, 13(2), 167-185.

James, W. (1921). The will to believe and other essays in popular philosophy. New York: Longmans, Green, and Co.

Joyce, J. (2005). How probabilities reflect evidence. Philosophical Perspectives, 19, 153-178.

Joyce, J. (2007). Epistemic deference and the case of chance. Proceedings of the Aristotelian Society, CVII, 187-206.

Keren, A. (2007). Epistemic authority, testimony and the transmission of knowledge. Episteme, 4(3), $368-381$.

Keren, A. (2014). Zagzebski on authority and preemption in the domain of belief. European Journal for Philosophy of Religion, 6(4), 61-76.

Korcz, K. A. (2000). The causal doxastic theory of the basing relation. Canadian Journal of Philosophy, 30(4), 525-550.

Raz, J. (1977). Promises and obligations. In P. M. S. Hacker \& J. Raz (Eds.), Law, morality and society (pp. 210-228). Oxford: Oxford University Press.

Raz, J. (1988). The morality of freedom. Oxford: Clarendon Press.

Raz, J. (1995). Ethics in the public domain: Essays in the morality of law and politics. Oxford: Oxford University Press.

Raz, J. (2009). Between authority and interpretation: On the theory of law and practical reason. Oxford: Oxford University Press.

Schaffer, J. (2003). Overdetermining causes. Philosophical Studies, 114, 23-45.

Strevens, M. (2012). Notes on Bayesian confirmation theory. Accessed May 24, 2017 http://www.nyu. edu/classes/strevens/BCT/BCT.pdf.

Swain, M. (1981). Reasons and knowledge. Ithaca, NY: Cornell University Press.

Zagzebski, L. (2012). Epistemic authority: A theory of trust, authority, and autonomy in belief. Oxford: Oxford University Press.

Zagzebski, L. (2014). Epistemic authority and its critics. European Journal for Philosophy of Religion, $6(4), 169-187$.

Zagzebski, L. (2016). Replies to Christoph Jäger and Elizabeth Fricker. Episteme, 13(2), 187-194. 